\title{
Intraoperative Perfusion Assessment in Mastectomy Skin Flaps: How Close are We to Preventing Complications?
}

\author{
Nima Khavanin, MD ${ }^{1}$ Cecil Qiu, BA ${ }^{2}$ Halley Darrach, BS ${ }^{1}$ Franca Kraenzlin, MD ${ }^{1}$ \\ George Kokosis, MD ${ }^{1}$ Tinglu Han, MD $^{3}$ Justin M. Sacks, MD, MBA, FACS ${ }^{1}$
}

1 Department of Plastic and Reconstructive Surgery, The Johns
Hopkins University School of Medicine, Baltimore, Maryland
2 Division of Plastic and Reconstructive Surgery, Northwestern
University, Feinberg School of Medicine, Chicago, Illinois
${ }^{3}$ Department of Plastic and Reconstructive Surgery, Plastic Surgery
Hospital, CAMS, PUMC, Beijing, China

J Reconstr Microsurg 2019;35:471-478.

\begin{abstract}
Address for correspondence Justin M. Sacks, MD, MBA, FACS, Department of Plastic and Reconstructive Surgery, Johns Hopkins Outpatient Center, 601 North Caroline Street, Suite 2114C, Baltimore, MD 21287 (e-mail: jmsacks@jhmi.edu).
\end{abstract}

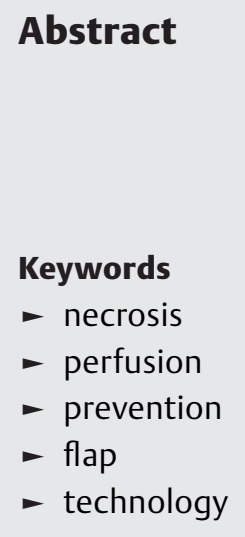

Background Mastectomy flap necrosis is the source of considerable morbidity and cost following breast reconstruction. A great deal of effort has been put forth to predicting and even preventing its incidence intraoperatively.

Methods A review of the literature was performed evaluating the evidence of mastectomy skin flap perfusion technologies.

Results Multiple technologies have leveraged spectroscopy and/or angiography to provide real-time assessment of flap perfusion, including indocyanine green, fluorescein, and light-based devices.

Conclusion This manuscript endeavors to review the evidence on mastectomy skin flap perfusion analysis, highlighting the benefits, and downsides of the current technologies and identifying exciting areas of future research and development.
In 2016, nearly 110,000 women in the United States alone underwent breast reconstruction by members of the American Society of Plastic Surgeons (ASPS), of which roughly 90,000 elected for tissue expander-implant or implant only techniques. ${ }^{1}$ These rates continue to rise as breast reconstruction establishes itself as one of the main pillars in the treatment of breast cancer patients. ${ }^{2}$ This is in part because the benefits of reconstruction are manifold, restoring a patient's form and sense of self in addition to providing psychosocial wellbeing and aesthetic benefits. ${ }^{2-5}$

Nonetheless, mastectomy interrupts the axial blood supply to the skin overlying the breast, creating a relatively hypovascular milieu and skin flaps prone to wound breakdown and tissue necrosis in 3 to $33 \%$ of cases. ${ }^{6-9}$ Particularly in prosthetic breast reconstruction, the viability of these

(D) Nima Khavanin's ORCID is http://orcid.org/0000-0002-8050-5935. mastectomy skin flaps is of utmost importance to prevent implant exposure leading to explanation, delays in adjuvant chemoradiation, and possible reconstructive failure. ${ }^{10,11}$ To the plastic surgeon, mastectomy flap necrosis should represent a "never event;" however, we lack the tools to make this the reality.

As such, predicting the risk for mastectomy flap necrosis intraoperatively has been the subject of much research lately. ${ }^{12-14}$ Techniques using fluorescein ${ }^{14}$ or indocyanine green $^{13}$ angiography have yielded mixed results. ${ }^{13,15,16}$ Translating intraoperative measurements of ischemia, whether quantitative or visual, to full-thickness necrosis has proven challenging, particularly in the context of the hemodynamic changes that occur during and after surgery. Downsides including cost, ${ }^{13}$ device bulkiness, risk of allergic reaction, ${ }^{17}$ and challenges interpreting output have prevented their widespread incorporation into clinical received

September 24, 2018

accepted after revision

January 19, 2019

published online

February 21, 2019
Copyright (c) 2019 by Thieme Medical Publishers, Inc., 333 Seventh Avenue, New York, NY 10001, USA. Tel: +1(212) 584-4662.
DOI https://doi.org/ 10.1055/s-0039-1679958. ISSN 0743-684X. 
practice, the need for a more simple and reliable method persists.

To this end, our manuscript endeavors to review the evidence on mastectomy skin flap perfusion analysis, highlighting the benefits and downsides of the current techniques and identifying areas of future research and development.

\section{Breast Blood Supply}

The unoperated breast has a rich blood supply from multiple arterial sources that give rise to the perforators that perfuse the parenchyma and feed into the subdermal plexus. Redundant perfusion via the internal mammary, lateral thoracic, intercostal, and thoracoacromial artery perforators (-Fig. 1) allows for the safe manipulation of the breast tissues based on any of the above vascular pedicles. The internal mammary, or internal thoracic, perforators enter the superomedial aspect of the breast and are estimated to provide approximately $60 \%$ of its vascular supply. ${ }^{18}$ Superolaterally the lateral thoracic vessels predominate and superiorly the pectoral branch of the thoracoacromial artery. Finally, the intercostal artery provides lateral intercostal perforators as well as anterior intercostal perforators which supply the lateral and central/inferior aspects of the breast, respectively.

The venous drainage of the breast is via two interconnecting systems. The deep system parallels the arterial supply with venous perforators paired to their respective arteries. The superficial system, however, is comprised of a rich subdermal venous plexus that lies in communication with both the deep system of the breast as well as the surrounding superficial system of the body. ${ }^{19,20}$

Mastectomy interrupts the axial perfusion of the overlying breast skin, leaving the relatively hypovascular skin

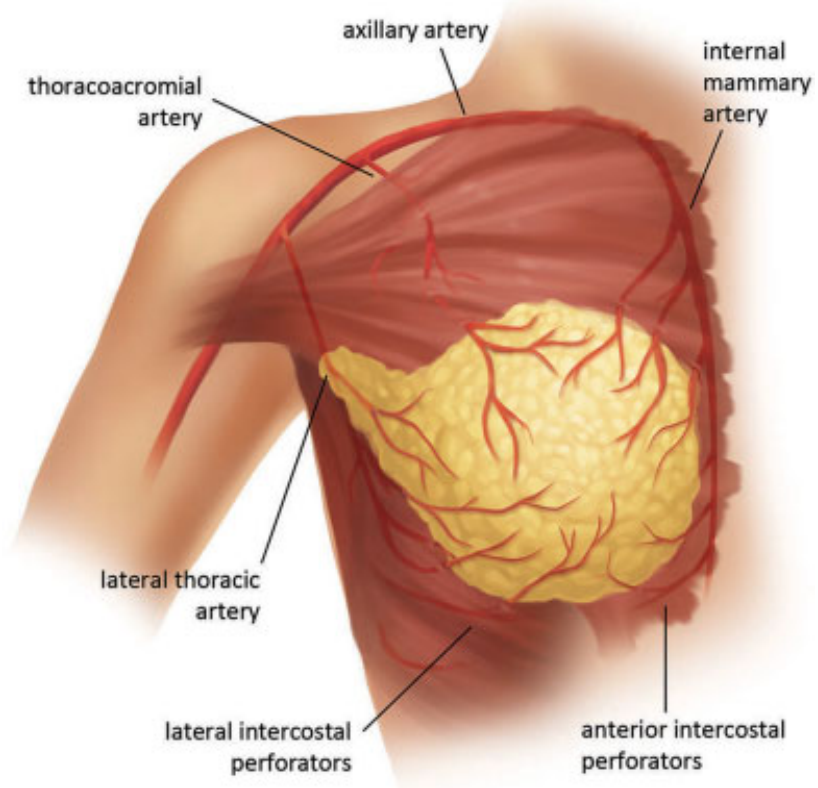

Fig. 1 Native blood supply of the breast. Artist rendering of the primary, axial blood supply of the breast via the internal mammary, thoracoacromial, lateral thoracic, and internal artery perforators. flaps dependent on random pattern perfusion and drainage through the subdermal plexus. As such thicker mastectomy flaps with an appropriate amount of subcutaneous fat preserve more of the tissue's blood supply and may even reduce the risk of flap necrosis, ${ }^{21}$ although this must be balanced with an increased risk of leaving behind breast tissue. Both the distal flap edges and beneath the nipple-areola complex, where additional margins are typically resected, are placed in relatively high risk for necrosis.

\section{Risk of Flap Necrosis}

The true risk of mastectomy skin flap necrosis following immediate prosthetic reconstruction is difficult to pinpoint and a broad range of estimates have been reported within the literature. $^{6-9}$ This is in part due to the variations in the definition of flap necrosis across studies. Full-thickness necrosis is rare and occurs on the order of 3 to $9 \%$ across studies; partial thickness necrosis rates have been reported has high as 30 to $40 \%{ }^{6,7,22-25}$ Scales, including the SKIN score more precisely delineate the depth of an area of tissue injury, ${ }^{26}$ but no one system has been broadly adopted by the research community.

Moreover, estimates of average, population-level risk are not always relevant to the individual patient, ${ }^{27,28}$ and in the case of flap necrosis, factors such as smoking status, mastectomy technique, flap thickness, and flap length play a considerable role in determining risk. Because of this heterogeneity, meta-analysis of flap necrosis rates proved to be challenging and of dubious value; to our knowledge, no such attempt has been published within the literature.

\section{Clinical Examination}

Perhaps the oldest and most widely used method to assess mastectomy skin flaps, several studies have demonstrated the unpredictability of clinical exam in accurately and precisely predicting flap necrosis. Surgeons can evaluate for flap length or thinness, uneven flaps, ecchymosis, capillary refill, color, temperature, or bleeding from skin edges, and trim back to healthy tissue as needed. However, when decisions are based on clinical exam alone, flap necrosis rates remain elevated between $4 \%$ to $40 \%{ }^{6,7,22-24}$ Even with a "lowthreshold" to excise questionable skin, necrosis rates can be as high as $27 \%,{ }^{14}$ with multiple large series reporting specificities for clinical exam in the 10 to $30 \%$ range. ${ }^{29-31}$ Not only has clinical exam been demonstrated to be inferior to more objective methods of perfusion assessment, ${ }^{15,29,32}$ but the degree/thickness of the associated necrosis tends to be more severe. ${ }^{33}$ In general, a concerning exam represents a "tip of the iceberg," as only the most foregone of tissues will declare themselves on the table to the naked eye.

Several clinical variables, beyond the physical exam and patient comorbidities, have also been correlated with the incidence of flap necrosis. The volume and weight of the tissue expander applies pressure on the already tenuous flaps and can exacerbate tissue ischemia and necrosis. The weight of the mastectomy specimen is also a useful variable, 
both in and of itself, but also as a correlate for flap length and expander volume/weight. ${ }^{34}$ It is also important to note that clinical flap assessment is particularly challenging in patients with darker skin as the ability to perceive color changes and capillary refill may be obscured by high melanin concentrations. $^{35}$

\section{Angiography}

\section{Fluorescein}

The use of fluorescein to evaluate mastectomy skin flap viability was first described in the late 1970s by Singer and colleagues. $^{36}$ Their cohort demonstrated its merit in identifying healthy and well perfused flaps but acknowledged its limitation in precisely delineating the extent and thickness of necrosis in concerning ones. After the completion of mastectomy, a weight based $(10-15 \mathrm{mg} / \mathrm{kg})^{23,36}$ or fixed (approximately $500-1,000 \mathrm{mg})^{14,37}$ dose of fluorescein is administered intravenously and allowed 15 minutes to circulate throughout the flaps. A Wood's lamp or a more modern "black light," that emits 320 to $500 \mathrm{~nm}$ wavelength ultraviolet light, is then turned on and used to visibly assess the diffusion of the fluorescein throughout the tissues. Well perfused flaps will glow yellow, whereas poorly perfused regions appear blue, and intermediate areas as yellow with blue mottling. The dye is generally well tolerated and excreted within the urine in 12 to 18 hours; side effects are rare and most commonly include nausea and vomiting. Allergic reactions, typically comprised of urticaria and fever, have been reported in $0.6 \%$ of patients, and more sever adverse including vasovagal reactions or cardiopulmonary events are rare. ${ }^{37-39}$

Several studies ${ }^{14,23,37}$ have built upon Singer's original data demonstrating a very high positive predictive value for areas that fluoresce of well over $90 \%$, but blue areas continue to underpredict flap survival with false negative rates as high as $75 \%{ }^{37}$ Therefore, while using fluorescein to guide skin resection certainly decreases flap necrosis (to as low as 3\% in one study ${ }^{14}$ ), as much as $80 \%$ of the resected area may actually go on to survive. ${ }^{23}$ Surgeons are again left with clinical judgement to discern between true and false negatives, often weighing the size and location of hypoperfusion, flap thickness, and signs of retraction or electrocautery injury, as well as the patient's radiation history. ${ }^{37}$ The presence of vasoconstrictive agents, such as epinephrine from a tumescent mastectomy, ${ }^{40}$ may also limit dye uptake and study results. The primary limitation of this technique, and many of others described in the literature, is that they afford only a single snapshot of perfusion even though blood flow is constantly changing in the perioperative period due to a patient's hemodynamic state, cholinergic tone, and the insult of a surgical procedure. Porcine data have demonstrated an increase in flap fluorescence area of roughly $20 \%$ within 24 hours after flap elevation. ${ }^{41}$

No studies to date have evaluated cost, patient reported outcomes, or aesthetic results in patients managed using intraoperative fluorescein angiography. Future prospective randomized data will be necessary to compare algorithms using fluorescein and clinical judgement against other techniques for flap evaluation.

\section{Indocyanine Green}

Indocyanine green (ICG) is an intravenously administered, biliary-excreted dye that circulates throughout tissues and emits infrared light upon excitation. Compared with fluorescein, the dye has a faster uptake into the tissues requiring only about 2 minutes before evaluation. Molecularly, ICG is larger than fluorescein (775 vs. $375 \mathrm{kD}$ ) and more likely to bind to plasma proteins, making it more likely to stay within the intravascular compartment and resulting in a faster washout (2.5 minutes half-life vs. 23 minutes). ${ }^{42,43}$ These properties not only decrease operative/evaluation time but also result in a superior side effect profile ${ }^{44,45}$ and allow for multiple injections and image captures during the same procedure. Although rare, allergic responses, including anaphylaxis, have been reported following ICG administration. ${ }^{46}$ A typical dose in adults is $25 \mathrm{mg}$ of ICG, with a recommended maximum dose of $2 \mathrm{mg} / \mathrm{kg}$. ${ }^{47}$ Other cited benefits of ICG angiography compared with fluorescein include a more gentle learning curve that is not dependent on the operators handling of a Wood's lamp as well as the potential for providing a quantified output ( - Table 1 ). ${ }^{48}$

Several commercially available devices exist to evaluate ICG derived fluorescence in human tissues, including: the SPY Elite System (Novadaq, San Jose, CA; - Fig. 2), FLARE (Curadel LLC Marlborough, MA), PDENeo (Hamamatsu Photonics Hamamatsu City, Shizuoka, Japan), and Fluobeam 800 (Fluoptics, Cambridge, MA). ${ }^{48}$ These devices include a sensor and a source that emits infrared light in the 760 to $785 \mathrm{~nm}$ wavelength range that excites the ICG molecule and triggers fluorescence in the 820 to $840 \mathrm{~nm}$ range. ${ }^{49}$ The SPY and FLARE systems further provide software that is able to covert fluorescence into a quantitative measurement. Although there are clinical or preclinical data for each of these systems in mastectomy flap perfusion analysis; the SPY system is by far the most extensively reported but also the most expensive with a device cost of $\$ 250,000$ and per use cost of $\$ 650.48$

First described in humans in $1999,{ }^{50}$ this technology was first applied to mastectomy flap evaluation in the early 2000s with De Lorenzi et al's proof of concept demonstrating a difference in perfusion patterns between native nipples and those elevated with the mastectomy skin flap. ${ }^{51}$ Newman et al retrospectively reviewed ICG fluorescence data for 20 patients undergoing immediate tissue expander based breast reconstruction, including nine with flap necrosis, and in hindsight demonstrated a 95\% correlation between intraoperative imaging and complications with a $100 \%$ sensitivity and $91 \%$ specificity. ${ }^{52}$ As surgeons began incorporating this technology into their intraoperative decision making, analyses of pre- and post-ICG implementation cohorts demonstrated a decrease in not only mastectomy skin flap necrosis but also unplanned reoperation rates by more than $50 \%{ }^{15,53}$ Prospective comparisons to clinical exam have similarly demonstrated improved outcomes with intraoperative laser assisted ICG angiography. ${ }^{14,23}$

Not unlike fluorescein, early adopters of ICG faced the dilemma of overly conservative and aggressive resections threatening potentially viable tissues. Where ICG-based systems differed, however, was in their ability to quantify 
Table 1 Pros and cons of different techniques

\begin{tabular}{|c|c|c|c|}
\hline & Indocyanine green angiography & Fluorescein dye angiography & Near-infrared spectroscopy \\
\hline Pros & $\begin{array}{l}\text { - Quantitative analysis } \\
\text { - Large body of literature } \\
\text { - Faster dye washout than fluor- } \\
\text { escein } \\
\text { - Visualize perfusion throughout } \\
\text { entire flap } \\
\text { - More tolerable side effect pro- } \\
\text { file than fluorescein }\end{array}$ & $\begin{array}{l}\text { - Relatively cheap } \\
\text { - Handheld device } \\
\text { - Available for over } 40 \text { years }\end{array}$ & $\begin{array}{l}\text { - Handheld device } \\
\text { - Relatively Cheap } \\
\text { - Rapid serial measurements } \\
\text { - Dye-free system } \\
\text { - Quantitative measurement } \\
\text { - outcome (oxygenation \%) } \\
\text { - Easily used outside of OR }\end{array}$ \\
\hline Cons & $\begin{array}{l}\text { - Intravenous dye-based } \\
\text { - Serial evaluation limited by dye } \\
\text { - Risk of allergic reaction } \\
\text { - Confounded by epinephrine } \\
\text { - Requires specialized/bulky } \\
\text { machinery } \\
\text { - Questionable cost-efficacy } \\
\text { (approximately } \$ 650 / \text { use) }\end{array}$ & $\begin{array}{l}\text { - User dependent results } \\
\text { - Intravenous dye-based } \\
\text { - Serial evaluation limited by dye } \\
\text { - Risk of allergic reaction } \\
\text { - Confounded by epinephrine } \\
\text { - Requires Wood's lamp } \\
\text { - Relative paucity of outcomes data }\end{array}$ & $\begin{array}{l}\text { - Lack of clinical outcomes data } \\
\text { - Highly localized measure- } \\
\text { ments, unable to assess entire } \\
\text { flap } \\
\text { - Potentially confounded by } \\
\text { other chromophores (melanin) }\end{array}$ \\
\hline $\begin{array}{l}\text { Predictive } \\
\text { accuracy }^{\text {a }}\end{array}$ & $\begin{array}{l}\text { APU: } 20,{ }^{54} \text { Sen: } 100, \text { Spec } 28, \\
\text { APU: } 15,54 \text { Sen: } 100, \text { Spec } 51, \\
\text { APU: } 10,54 \text { Sen: } 100, \text { Spec } 72, \\
\text { APU: } 7,{ }^{12} \text { Sen: } 88, \text { Spec } 83, \\
\text { APU: } 6,{ }^{12} \text { Sen: } 75, \text { Spec } 83, \\
\text { APU: } 3{ }^{12} \text { Sen: } 38, \text { Spec } 83\end{array}$ & $\begin{array}{l}\text { Losken et al, }{ }^{37} \text { Sen: } 75, \text { Spec: } 71 \\
\text { Phillips et al, }{ }^{23} \text { Sen: } 90, \text { Spec: } 30\end{array}$ & $\mathrm{~N} / \mathrm{A}$ \\
\hline
\end{tabular}

Abbreviations: APU, absolute perfusion units; N/A, not available; OR, operating room; Sen, sensitivity; Spec, specificity.

andocyanine green data based on data using the SPY Elite system.

perfusion. The SPY system uses its proprietary software, the SPY-Q (Novadaq, San Jose, CA), to calculate and report both absolute perfusion as an integer or relative perfusion as a percentage of a selected reference area within the field. These analyses can be done either in real time intraoperatively or post hoc. Mattison et $\mathrm{al}^{54}$ used different thresholds to demonstrate that a higher cut-off value does not necessarily improve sensitivity and may even come at an increased cost in specificity, positive predictive value, and the unnecessary resection of as much as $10 \mathrm{~cm}^{2}$ or more of skin. As they search for an accurate cut-off, some authors have advocated for the use of relative fluorescence in assessing perfusion, ${ }^{55,56}$ but these measurements are more prone to interuser variability than absolute cut-offs. ${ }^{12,55,57}$ Interestingly, these measurements appear to be confounded by smoking status, use of epinephrine (tumescent mastectomy), and even skin
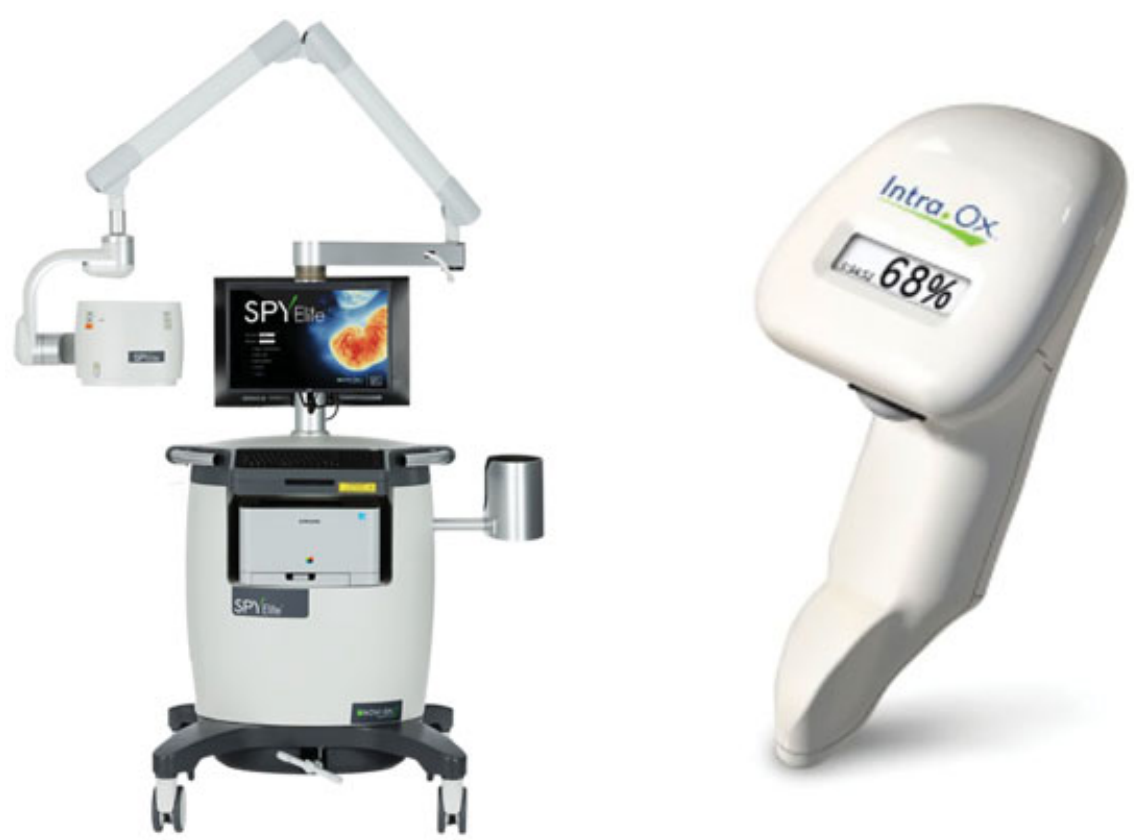

Fig. 2 Left, SPY Elite system for indocyanine green angiography. Right, ViOptix Intra.Ox handheld tissue oximeter. 
pigmentation or a history of hypertension, ${ }^{55}$ but the relationships remain incompletely described. Sanniec et al is the only group to date who described their algorithm for interpreting and applying these quantitative data in clinical practice; however, no prospective randomized data exist to support one protocol or perfusion cut-off over another. ${ }^{58}$

Overall, the use of ICG or fluorescein angiography does not appear to decrease mastectomy skin loss. If anything, their use may come at the increased cost of debriding healthy skin to ensure that all devitalized tissues are removed and to prevent the downstream cost and morbidity associated with flap necrosis. One study by Rinker ${ }^{14}$ compared the area of resection with ICG, fluorescein and clinical exam ( - Table 2); however, these numbers are difficult to interpret due to the discrepancies in flap necrosis rates across the cohorts. Other studies comparing intraoperative predictions to clinical flap necrosis within the same patients demonstrate as much as 3 to $6 \mathrm{~cm}^{2}$ of excess skin loss with ICG or $19 \mathrm{~cm}^{2}$ with fluorescein that is corroborated by the modest specificities for these techniques (-Table 2 ). In the correct patient, this excess cost in tissue may be justified by the improvement in patient outcomes and preventing delays in adjuvant chemoradiation.

Overall, ICG angiography rates in immediate breast reconstruction have been on the rise in recent years. ${ }^{59}$ Despite the high upfront cost of an ICG detector as well as cost per use associated with the dye and other operative room equipment, Duggal et al also demonstrates a $\$ 614$ cost saving per patient in reducing flap necrosis rates from 44 to $25 \%$ and reoperation rates from $14 \%$ to $6 \% .{ }^{15}$ Other studies have not replicated these findings, however, particularly in the setting of a more modest reduction in adverse events. ${ }^{13,59}$ Kanuri et $\mathrm{al}^{13}$ performed a retrospective subgroup analysis identifying smoking, BMI $>30 \mathrm{~kg} / \mathrm{m}^{2}$, and mastectomy weight greater than $800 \mathrm{~g}$ as high-risk features that result in a net cost-savings. Further research will be necessary to better understand the cost and benefits associated with ICG angiography and to identify the subgroup of patients in whom this technology is most cost effective.

\section{Spectroscopy}

Light-based spectroscopy generally takes advantage of the hemoglobin molecule's ability to absorb or reflect light at various wavelengths to provide an estimate of either perfu- sion or tissue oxygenation. ${ }^{60,61}$ These techniques benefit from being noninvasive in nature and have multiple applications in different tissues and clinical scenarios.

Although limited in its application to mastectomy skin flaps, Laser Doppler flowmetry is one such hand-held technique that has more commonly been applied to breast free flaps. ${ }^{62,63}$ In this technique, moving blood cells within the dermal plexus cause a back scattering of photons that provides information on their speed and concentration as surrogates for perfusion. Laser speckle contrast imaging is a similar camera-based technique that is able to scan a large area of skin (typically $15 \mathrm{~cm} \times 15 \mathrm{~cm}$ ) and demonstrate the reflection of light by moving red blood cells in the dermal plexus, typically as a speckle pattern on the camera sensor giving the technique its name. ${ }^{60}$ Polarized light has also been described to visually assess circulation in tissues of interest. After polarized light in the hemoglobin spectrum (548 nm wavelength) is directed toward the target, a majority of it is either reflected off its surface in an orthogonal plane or scattered by hemoglobin molecules. Once the orthogonally reflected light is filtered by a polarizer, the remaining, transmitted light is that which has been scattered by hemoglobin; this is picked up by a charge coupled device camera to provide real-time images of the microcirculation at a similar contrast level to images obtained using fluorescent dyes. ${ }^{64}$ Although the latter two methods provide qualitative data on perfusion, several algorithms have been developed to provide estimates of red blood cell concentration or other values based on pixel values from the images. ${ }^{61,65}$

Although several other similar techniques have been described, only one has been directly applied to mastectomy skin flaps to date and will be discussed in further detail.

\section{Near-Infrared Oximetry}

Near-infrared spectroscopy samples of hemoglobin in specific areas of tissue adjacent to a sensor, providing highly localized measurements of tissue oxygenation. It is based on the principle that oxygenated and deoxygenated hemoglobin are chromophores that interact with light differently. The device directs near-infrared light toward the tissue of interest, and its intensity, as it returns to the sensor, allows for the calculation of a relative percentage of the two molecules. ${ }^{66}$ The ViOptix T.Ox (ViOptix, Inc., Fremont, CA) has already been demonstrated to be specific and sensitive in the

Table 2 Comparisons of prospective results for skin resection area and specificity

\begin{tabular}{|l|l|l|l|}
\hline & Rinker $2016^{14}$ & Phillips et al $2012^{23}$ & Mattison et al 2016 \\
\hline Fluorescein & $\begin{array}{l}6.2 \mathrm{~cm}^{2} \text { skin resection 3\% flap } \\
\text { necrosis }\end{array}$ & $\begin{array}{l}\text { Overpredicted necrosis by } \\
18.86 \mathrm{~cm}^{2} ; \text { Sens: } 90 \%, \text { Spec: } 30 \%\end{array}$ & \\
\hline ICG & $\begin{array}{l}5.4 \mathrm{~cm}^{2} \text { skin resection 14\% flap } \\
\text { necrosis }\end{array}$ & $\begin{array}{l}\text { Overpredicted necrosis by } \\
6.57 \mathrm{~cm}^{2} ; \text { Sens: } 90 \%, \text { Spec: } 50 \%\end{array}$ & $\begin{array}{l}\text { Predicts } 3.23 \mathrm{~cm}^{2} \text { or more } \\
\text { necrosis than exam specificity of } \\
68.1 \%\end{array}$ \\
\hline Clinical exam & $\begin{array}{l}6.5 \mathrm{~cm}^{2} \text { skin resection 27\% flap } \\
\text { necrosis }\end{array}$ & & \\
\hline
\end{tabular}

Abbreviation: ICG, indocyanine green. 
detection of postoperative vascular compromise in free tissue transfer, ${ }^{67,68}$ identifying impending complications earlier than alternatives modalities. ${ }^{69}$ Only one study has used the T.Ox intraoperatively on mastectomy skin flaps, demonstrating a significantly greater reduction in oxygenation in tissue that becomes necrotic compared with healthy tissues. $^{70}$

Several factors unrelated to tissue oxygen saturation can affect near-infrared oximetry measurements, including instrumentation of the device, ambient light, melanin concentration, and the presence of additional chromophores including methylene blue. Additionally, single sensor detectors are unable to effectively distinguish the effects of absorption versus tissue scattering on light intensity at the sensor. To this end, a more recently FDA (Food and Drug Administration) approved device, the Intra.Ox (ViOptix, Inc., Fremont, CA; - Fig. 2), is designed with multiple sensors specifically to overcome these limitations for intraoperative use. The device is wireless, battery operated, and handheld allowing for multiple, rapid measurements throughout the procedure without the need for dye or bulky equipment (-Table 1). The device also provides information on the quality its reading to improve interuser reliability. Lohman et al identified $30 \%$ oxygenation predicted tissue necrosis in porcine fasciocutaneous flaps ${ }^{66}$; however, this newest generation of technology has yet to be applied in human mastectomy skin flaps.

\section{Future Directions}

As these various technologies vie to define their role in the assessment of mastectomy skin flap perfusion, future studies will have to demonstrate each one's potential value to patient care, specifically how they can each improve patient outcomes and curb medical costs. Within the issue of cost is entangled the question of the target population. For more expensive technologies with a high per use cost (e.g., ICG angiography) indiscriminate use may not prove feasible, and a more targeted, high-risk population will need to be defined. But does this apply to reusable, dye-free techniques like near-infrared spectroscopy? Is one technology clearly superior in all populations, or should the technique for flap assessment be selected on a case-bycase basis? Both theoretical and retrospective reviews of cost and benefit will allow us to better understand each technology's strengths and limitations and to carve out its niche in clinical practice.

Studies evaluating these technologies in prepectoral breast reconstruction will also be useful given the recent resurgence of this technique. Many centers have begun to incorporate indocyanine green angiography in their flap assessment and pocket selection algorithm; however, the data are not yet available within the literature. In the context of questionable mastectomy flap viability, the additional layer of vascularized muscle may protect an expander from exposure and its downstream sequalae. In these select cases, pocket exchange at the time of expander implant exchange may prove to be a safer alternative.
The best time for flap assessment also remains an unanswered question. Perfusion measurements will undoubtedly vary immediately following mastectomy to after device insertion and even after skin closure with varying degrees of tension. The patient's hemodynamic state is also likely to fluctuate throughout the perioperative period. Ideally, evaluation occurs intraoperatively when surgeons have the most control over changing aspects of the case to avoid a complication. Most studies to date have evaluated skin flaps prior to reconstruction, and it remains to be seen what changes should be expected after that. In general, additional stress on the flaps should be avoided after assessment to not confound the results.

With regards to outcomes, we currently lack prospective data to validate most of the regiments described within the literature. Different authors have put forth varying criteria for the resection of skin based on qualitative and/or quantitative assessment of its perfusion; which one appropriately identifies at risk tissue with the least amount of collateral damage? How do patient factors, including skin pigmentation or blood pressure weight into this? Also implicit to all of this is the issue of interuser variability for each technique. With several therapeutic options available beyond simply resecting at risk skin, including application of vasodilatory substances, such as nitroglycerine ointment, switching from single-stage to two-stage reconstruction, pocket selection, deflation of tissue expanders, or even delaying reconstruction altogether, we must better understand how to interpret these new objective data and navigate the intraoperative decision-making process.

\section{Conclusion}

Although objective assessment of tissue perfusion seems to have already delivered on its promise to prevent complications, in the era of value-based care, further research is necessary to do so reliably and efficiently on an even larger scale.

Conflict of Interest

None declared.

\section{References}

1 "2016 Plastic Surgery Statistics Report." American Society of Plastic Surgeons, 2017. Available at: https://www.plasticsurgery.org/documents/News/Statistics/2016/plastic-surgery-statistics-full-report-2016.pdf. Accessed January 13, 2017

2 Fischer JP, Fox JP, Nelson JA, Kovach SJ, Serletti JM. A longitudinal assessment of outcomes and healthcare resource utilization after immediate breast reconstruction-comparing implant- and autologous-based breast reconstruction. Ann Surg 2015;262(04):692-699

3 Albornoz CR, Bach PB, Mehrara BJ, et al. A paradigm shift in U.S. Breast reconstruction: increasing implant rates. Plast Reconstr Surg 2013;131(01):15-23

4 Albornoz CR, Cordeiro PG, Farias-Eisner G, et al. Diminishing relative contraindications for immediate breast reconstruction. Plast Reconstr Surg 2014;134(03):363e-369e

5 Slavin SA, Schnitt SJ, Duda RB, et al. Skin-sparing mastectomy and immediate reconstruction: oncologic risks and aesthetic results in patients with early-stage breast cancer. Plast Reconstr Surg 1998;102(01):49-62 
6 Mlodinow AS, Fine NA, Khavanin N, Kim JY. Risk factors for mastectomy flap necrosis following immediate tissue expander breast reconstruction. J Plast Surg Hand Surg 2014;48(05): 322-326

7 Khavanin N, Jordan S, Lovecchio F, Fine NA, Kim J. Synergistic interactions with a high intraoperative expander fill volume increase the risk for mastectomy flap necrosis. J Breast Cancer 2013;16(04):426-431

8 Gdalevitch P, Van Laeken N, Bahng S, et al. Effects of nitroglycerin ointment on mastectomy flap necrosis in immediate breast reconstruction: a randomized controlled trial. Plast Reconstr Surg 2015;135(06):1530-1539

9 Yun MH, Yoon ES, Lee BI, Park SH. The effect of low-dose nitroglycerin ointment on skin flap necrosis in breast reconstruction after skin-sparing or nipple-sparing mastectomy. Arch Plast Surg 2017;44(06):509-515

10 Spear SL, Masden D, Rao SS, Nahabedian MY. Long-term outcomes of failed prosthetic breast reconstruction. Ann Plast Surg 2013;71 (03):286-291

11 Peled AW, Stover AC, Foster RD, McGrath MH, Hwang ES. Longterm reconstructive outcomes after expander-implant breast reconstruction with serious infectious or wound-healing complications. Ann Plast Surg 2012;68(04):369-373

12 Munabi NC, Olorunnipa OB, Goltsman D, Rohde CH, Ascherman $J A$. The ability of intra-operative perfusion mapping with laserassisted indocyanine green angiography to predict mastectomy flap necrosis in breast reconstruction: a prospective trial. J Plast Reconstr Aesthet Surg 2014;67(04):449-455

13 Kanuri A, Liu AS, Guo L. Whom should we SPY? A cost analysis of laser-assisted indocyanine green angiography in prevention of mastectomy skin flap necrosis during prosthesis-based breast reconstruction. Plast Reconstr Surg 2014;133(04):448e-454e

14 Rinker B. A comparison of methods to assess mastectomy flap viability in skin-sparing mastectomy and immediate reconstruction: a prospective cohort study. Plast Reconstr Surg 2016;137 (02):395-401

15 Duggal CS, Madni T, Losken A. An outcome analysis of intraoperative angiography for postmastectomy breast reconstruction. Aesthet Surg J 2014;34(01):61-65

16 Venturi ML, Mesbahi AN, Copeland-Halperin LR, Suh VY, Yemc L. SPY Elite's ability to predict nipple necrosis in nipple-sparing mastectomy and immediate tissue expander reconstruction. Plast Reconstr Surg Glob Open 2017;5(05):e1334

17 Su Z, Ye P, Teng Y, Zhang L, Shu X. Adverse reaction in patients with drug allergy history after simultaneous intravenous fundus fluorescein angiography and indocyanine green angiography. J Ocul Pharmacol Ther 2012;28(04):410-413

18 Larson JVNM, Senser SF, Patel KM. Breast anatomy for plastic surgeons. In: Neligan P, ed. Plastic Surgery. Vol. 5: Breast. Elsevier Inc.; 2018:1-14.e11

19 Ricbourg B. Applied anatomy of the breast: blood supply and innervation [Article in French]. Ann Chir Plast Esthet 1992;37 (06):603-620

20 Taylor GI, Caddy CM, Watterson PA, Crock JG. The venous territories (venosomes) of the human body: experimental study and clinical implications. Plast Reconstr Surg 1990;86(02):185-213

21 Larson DL, Basir Z, Bruce T. Is oncologic safety compatible with a predictably viable mastectomy skin flap? Plast Reconstr Surg 2011;127(01):27-33

22 Margulies AG, Hochberg J, Kepple J, Henry-Tillman RS, Westbrook $\mathrm{K}$, Klimberg VS. Total skin-sparing mastectomy without preservation of the nipple-areola complex. Am J Surg 2005;190(06): 907-912

23 Phillips BT, Lanier ST, Conkling N, et al. Intraoperative perfusion techniques can accurately predict mastectomy skin flap necrosis in breast reconstruction: results of a prospective trial. Plast Reconstr Surg 2012;129(05):778e-788e
24 McCarthy CM, Mehrara BJ, Riedel E, et al. Predicting complications following expander/implant breast reconstruction: an outcomes analysis based on preoperative clinical risk. Plast Reconstr Surg 2008;121(06):1886-1892

25 Turin SY, Li DD, Vaca EE, Fine N. Nitroglycerin ointment for reducing the rate of mastectomy flap necrosis in immediate implant-based breast reconstruction. Plast Reconstr Surg 2018; 142(03):264e-270e

26 Lemaine V, Hoskin TL, Farley DR, et al. Introducing the SKIN score: a validated scoring system to assess severity of mastectomy skin flap necrosis. Ann Surg Oncol 2015;22(09):2925-2932

$27 \mathrm{Kim}$ JY, Khavanin N, Jordan SW, et al. Individualized risk of surgical-site infection: an application of the breast reconstruction risk assessment score. Plast Reconstr Surg 2014;134(03): 351e-362e

28 Kim JY, Mlodinow AS, Khavanin N, et al. Individualized risk of surgical complications: an application of the breast reconstruction risk assessment score. Plast Reconstr Surg Glob Open 2015;3 (05):e405

29 Komorowska-Timek E, Gurtner GC. Intraoperative perfusion mapping with laser-assisted indocyanine green imaging can predict and prevent complications in immediate breast reconstruction. Plast Reconstr Surg 2010;125(04):1065-1073

30 Davies K, Allan L, Roblin P, Ross D, Farhadi J. Factors affecting postoperative complications following skin sparing mastectomy with immediate breast reconstruction. Breast 2011;20(01):21-25

31 Meretoja TJ, Rasia S, von Smitten KA, Asko-Seljavaara SL, Kuokkanen HO, Jahkola TA. Late results of skin-sparing mastectomy followed by immediate breast reconstruction. Br J Surg 2007;94 (10):1220-1225

32 Harless CA, Jacobson SR. Tailoring through technology: a retrospective review of a single surgeon's experience with implantbased breast reconstruction before and after implementation of laser-assisted indocyanine green angiography. Breast J 2016;22 (03):274-281

33 Diep GK, Hui JY, Marmor S, et al. Postmastectomy reconstruction outcomes after intraoperative evaluation with indocyanine green angiography versus clinical assessment. Ann Surg Oncol 2016;23 (12):4080-4085

34 Yalanis GC, Nag S, Georgek JR, et al. Mastectomy weight and tissue expander volume predict necrosis and increased costs associated with breast reconstruction. Plast Reconstr Surg Glob Open 2015;3 (07):e450

35 Polfer EM, Zimmerman RM, Tefera E, Katz RD, Higgins JP, Means KR Jr. The effect of skin pigmentation on determination of limb ischemia. J Hand Surg Am 2018;43(01):24-32.e1

36 Singer R, Lewis CM, Franklin JD, Lynch JB. Fluorescein test for prediction of flap viability during breast reconstructions. Plast Reconstr Surg 1978;61(03):371-375

37 Losken A, Styblo TM, Schaefer TG, Carlson GW. The use of fluorescein dye as a predictor of mastectomy skin flap viability following autologous tissue reconstruction. Ann Plast Surg 2008; 61(01):24-29

38 Johnson RN, McDonald HR, Schatz H. Rash, fever, and chills after intravenous fluorescein angiography. Am J Ophthalmol 1998;126 (06):837-838

39 Lira RP, Oliveira CL, Marques MV, Silva AR, Pessoa CdeC. Adverse reactions of fluorescein angiography: a prospective study. Arq Bras Oftalmol 2007;70(04):615-618

40 Khavanin N, Fine NA, Bethke KP, et al. Tumescent technique does not increase the risk of complication following mastectomy with immediate reconstruction. Ann Surg Oncol 2014;21(02):384-388

41 Pang CY, Neligan P, Nakatsuka T, Sasaki GH. Assessment of the fluorescein dye test for prediction of skin flap viability in pigs. J Surg Res 1986;41(02):173-181

42 Kuebler WM, Sckell A, Habler O, et al. Noninvasive measurement of regional cerebral blood flow by near-infrared spectroscopy and 
indocyanine green. J Cereb Blood Flow Metab 1998;18(04): 445-456

43 Meijer DK, Weert B, Vermeer GA. Pharmacokinetics of biliary excretion in man. VI. Indocyanine green. Eur J Clin Pharmacol 1988;35(03):295-303

44 Speich R, Saesseli B, Hoffmann U, Neftel KA, Reichen J. Anaphylactoid reactions after indocyanine-green administration. Ann Intern Med 1988;109(04):345-346

45 Benya R, Quintana J, Brundage B. Adverse reactions to indocyanine green: a case report and a review of the literature. Cathet Cardiovasc Diagn 1989;17(04):231-233

46 Olsen TW, Lim JI, Capone A Jr, Myles RA, Gilman JP. Anaphylactic shock following indocyanine green angiography. Arch Ophthalmol 1996;114(01):97

47 Gurtner GC, Jones GE, Neligan PC, et al. Intraoperative laser angiography using the SPY system: review of the literature and recommendations for use. Ann Surg Innov Res 2013;7(01):1

48 Griffiths M, Chae MP, Rozen WM. Indocyanine green-based fluorescent angiography in breast reconstruction. Gland Surg 2016;5(02):133-149

49 Marshall MV, Rasmussen JC, Tan IC, et al. Near-infrared fluorescence imaging in humans with indocyanine green: a review and update. Open Surg Oncol J 2010;2(02):12-25

50 Still J, Law E, Dawson J, Bracci S, Island T, Holtz J. Evaluation of the circulation of reconstructive flaps using laser-induced fluorescence of indocyanine green. Ann Plast Surg 1999;42(03):266-274

51 De Lorenzi F, Yamaguchi S, Petit JY, et al. Evaluation of skin perfusion after nipple-sparing mastectomy by indocyanine green dye. Preliminary results. J Exp Clin Cancer Res 2005;24(03): 347-354

52 Newman MI, Samson MC, Tamburrino JF, Swartz KA. Intraoperative laser-assisted indocyanine green angiography for the evaluation of mastectomy flaps in immediate breast reconstruction. J Reconstr Microsurg 2010;26(07):487-492

53 Sood M, Glat P. Potential of the SPY intraoperative perfusion assessment system to reduce ischemic complications in immediate postmastectomy breast reconstruction. Ann Surg Innov Res 2013;7(01):9

54 Mattison GL, Lewis PG, Gupta SC, Kim HY. SPY Imaging Use in Postmastectomy Breast Reconstruction Patients: Preventative or Overly Conservative? Plast Reconstr Surg 2016;138(01):15e-21e

55 Moyer HR, Losken A. Predicting mastectomy skin flap necrosis with indocyanine green angiography: the gray area defined. Plast Reconstr Surg 2012;129(05):1043-1048

56 Newman MI, Jack MC, Samson MC. SPY-Q analysis toolkit values potentially predict mastectomy flap necrosis. Ann Plast Surg 2013;70(05):595-598

57 Phillips BT, Fourman MS, Rivara A, et al. Comparing quantitative values of two generations of laser-assisted indocyanine green dye angiography systems: can we predict necrosis? Eplasty 2014;14: e44

58 Sanniec K, Teotia S, Amirlak B. Management of tissue ischemia in mastectomy skin flaps: algorithm integrating SPY angiography and topical nitroglycerin. Plast Reconstr Surg Glob Open 2016;4 (10):e1075

59 Chattha A, Bucknor A, Chen AD, Lee BT, Lin SJ. Indocyanine green angiography use in breast reconstruction: a national analysis of outcomes and cost in 110,320 patients. Plast Reconstr Surg 2018; 141(04):825-832

60 Olivier WA, Hazen A, Levine JP, Soltanian H, Chung S, Gurtner GC. Reliable assessment of skin flap viability using orthogonal polarization imaging. Plast Reconstr Surg 2003;112(02):547-555

61 Tesselaar E, Flejmer AM, Farnebo S, Dasu A. Changes in skin microcirculation during radiation therapy for breast cancer. Acta Oncol 2017;56(08):1072-1080

62 Hallock GG. Acoustic Doppler sonography, color duplex ultrasound, and laser Doppler flowmetry as tools for successful autologous breast reconstruction. Clin Plast Surg 2011;38(02):203-211

63 Figus A, Mosahebi A, Ramakrishnan V. Microcirculation in DIEP flaps: a study of the haemodynamics using laser Doppler flowmetry and lightguide reflectance spectrophotometry. J Plast Reconstr Aesthet Surg 2006;59(06):604-612, discussion 613

64 Groner W, Winkelman JW, Harris AG, et al. Orthogonal polarization spectral imaging: a new method for study of the microcirculation. Nat Med 1999;5(10):1209-1212

65 O'Doherty J, Henricson J, Anderson C, Leahy MJ, Nilsson GE, Sjöberg F. Sub-epidermal imaging using polarized light spectroscopy for assessment of skin microcirculation. Skin Res Technol 2007;13(04):472-484

66 Lohman RF, Ozturk CN, Djohan R, Tang HR, Chen H, Bechtel KL. Predicting skin flap viability using a new intraoperative tissue oximetry sensor: a feasibility study in pigs. J Reconstr Microsurg 2014;30(06):405-412

67 Lin SJ, Nguyen MD, Chen C, et al. Tissue oximetry monitoring in microsurgical breast reconstruction decreases flap loss and improves rate of flap salvage. Plast Reconstr Surg 2011;127 (03):1080-1085

68 Keller A. A new diagnostic algorithm for early prediction of vascular compromise in 208 microsurgical flaps using tissue oxygen saturation measurements. Ann Plast Surg 2009;62(05): 538-543

69 Lohman RF, Langevin CJ, Bozkurt M, Kundu N, Djohan R. A prospective analysis of free flap monitoring techniques: physical examination, external Doppler, implantable Doppler, and tissue oximetry. J Reconstr Microsurg 2013;29(01):51-56

70 Rao R, Saint-Cyr M, Ma AM, et al. Prediction of post-operative necrosis after mastectomy: a pilot study utilizing optical diffusion imaging spectroscopy. World J Surg Oncol 2009;7:91 